\title{
O EDUCADOR EM LÍNGUA DOMINANTE E O DESENVOLVIMENTO SUSTENTÁVEL
}

\author{
Maria Cecília Piccoli ${ }^{1}$
}

\begin{abstract}
RESUMO
Considerando questões de sustentabilidade, este artigo discute a correlação entre o ensino de inglês como língua dominante, educação e desenvolvimento sustentáveis. Grande importância é dada ao ensino da língua e das habilidades lingüísticas enquanto os aspectos educacionais que buscam a educação integral da pessoa e o desenvolvimento sustentável são negligenciados. Como a língua inglesa domina a comunicação entre pessoas e nações de diferentes culturas, é relevante preparar os professores para trabalharem como educadores reais, visando a educação integral da pessoa. Questões educacionais poderiam ser incluídas no processo de formação profissional dos professores de língua inglesa, pois os mesmos ainda não se reconhecem como educadores em potencial e tampouco se assumem como educadores reais.
\end{abstract}

PALAVRAS-CHAVE: Educação; Desenvolvimento Sustentável; Língua Dominante.

\begin{abstract}
Considering sustainability issues, this article discusses the correlation among teaching English as a Dominant Language, Sustainable Education and Development. Great importance is given for teaching language and linguistics skills while the educational aspects fostering the whole person education and sustainable development are neglected. As the English language dominates the communication among nations and people from different cultures and countries, it is relevant to prepare teachers to work as real educators fostering the entire person education. Educational issues should be included in the professional education process of the English language teachers because they still do not recognize themselves as potential educators nor assumes themselves as real educators.
\end{abstract}

KEY-WORDS: Education; Sustainable Development; Dominant Language.

\section{INTRODUÇÃO}

\footnotetext{
${ }^{1}$ Maria Cecília Piccoli é especialista em Ensino de Língua Estrangeira Moderna - Inglês e professora no Colégio Nossa Senhora de Sion em Curitiba, PR.
} 
Este artigo pretende despertar o educador que provavelmente existe dentro de cada professor, especialmente no de língua inglesa envolvido no processo educativo dentro de organizações escolares de ensino fundamental e médio. Percebe-se que o professor de língua estrangeira mantém-se afastado do contexto educacional propriamente dito e preocupa-se apenas em transmitir os conteúdos lingüísticos. Esses professores têm evitado considerar o ensino de língua estrangeira como parte relevante da educação integral do ser humano, desconhecendo muitas vezes as razões e os porquês do ensino de pelo menos uma língua estrangeira como aspecto fundamental na educação de sujeitos.

Os cursos de formação de professores especialistas não têm contemplado eficazmente os aspectos relativos à educação e formação de cidadãos. Somado a essa situação vemos ainda que em congressos, workshops e palestras de TEFL e de TESOL não são oportunizadas discussões que relacionem metodologias, abordagens e técnicas com temas de educação em língua inglesa. Fato esse que poderia enriquecer sobremaneira a formação dos aprendizes.

A educação em língua inglesa mencionada aqui não trata de aspectos de educação bilíngüe, mas sim da educação integral do ser humano. Educação como ação que transforma um ser humano em sujeito, cidadão, "espírito, coração, cabeça e mãos" (STERLING, 2001, p. 12). Esta educação é contínua, constante; ela cria, ensina e cultiva o espírito crítico e reflexivo de cada ser; permite o uso do espírito para perceber, do coração para sentir, da cabeça para pensar e das mãos para agir em prol da construção de um mundo mais justo.

A partir de observações de leituras, o presente artigo foi estruturado em três capítulos: Educação Integral; Educação e Desenvolvimento Sustentável; Educação e Língua Inglesa, nos quais discurso sobre educação e sua relação com desenvolvimento sustentável e ensino de língua inglesa, aspectos que considero relevantes para a valorização da vida no planeta Terra, neste início de milênio.

$\mathrm{Na}$ Conclusão são apresentados os aspectos considerados mais relevantes observados durante o processo de desenvolvimento da pesquisa que deu origem a este artigo e a relação dos mesmos com as necessidades da sociedade contemporânea. 
Como os temas tratados são ligados entre si, ultrapassam fronteiras e, como organismos interferem-se mutuamente pela imbricação entre os mesmos. Contudo, na medida do possível, os temas são mantidos separadamente para facilitar a percepção dos mesmos, reconhecendo a unidade dentro do todo e acatando o que nos sugere Edgar MORIN (2001, p. 25), pois: "Trata-se, ao mesmo tempo, de reconhecer a unidade dentro do diverso, o diverso dentro da unidade".

\section{Educação integral}

Com base nas discussões promovidas pela Pedagogia Crítica, a educação é aqui tratada como um todo complexo que relaciona a educação e o papel do professor. Educação como possibilidade de transformação do modelo social atual em realidade mais justa que permite e incentiva a inclusão de sujeitos. Papel de professor no mundo contemporâneo e a necessidade de formação de profissionais primeiramente engajados em educação, com aprofundamento em disciplinas e conteúdos específicos de uma determinada área.

Característico das relações humanas, o processo educativo não é apenas uma situação formal. Todos os seres humanos, independentemente de suas características individuais e culturais, são seres inacabados, inconclusos. É exatamente a consciência desse inacabamento que torna o ser humano educável (FREIRE, 2001). Ser educável é estar em situação de abertura ao conhecimento, é ter consciência das incertezas e dúvidas, é aceitar que o conhecimento que até então se possui já não dá mais conta de responder às dúvidas do momento. A situação de educabilidade é percebida pelo aparecimento de questionamentos e dúvidas originados pela incerteza.

Para FREIRE (1996), perguntar é essencial, pois é a partir da pergunta que o ser se confirma inacabado. Portanto, é fundamental educar para a pergunta, incentivála e permiti-la, pois é dela e da dúvida gerada pelo estranhamento que vêm o conhecimento e a transformação. A "educação da pergunta aguça, estimula e reforça a curiosidade" (FREIRE, 2001, p. 19) permitindo ao sujeito agir, interagir, tornar-se agente e transformador de sonho em realidade.

Procurar respostas, mesmo sabendo-as provisórias, pode viabilizar a 
construção de ações transformadoras. Esta procura incita-nos à pesquisa num processo que pode transformar situações injustas em justas, desequilíbrio em equilíbrio. Portanto, a educação que discutimos sob esse prisma promove uma atitude crítica e pressupõe o ensino não só de habilidades específicas mas também da capacidade de interrogação e questionamento, que devolve o sujeito à incerteza, preparando-o para trabalhar novamente em busca de respostas enquanto cria certezas provisórias que também lhe darão condições, mesmo que efêmeras, de sobrevivência. Certezas provisórias são patamares alcançados momentaneamente, nos quais são criadas certezas, edificadas a partir de representações ideológicas da realidade. São certezas sociais e políticas provisórias porque são dinâmicas, mutáveis, transformáveis pelo contexto espacial e temporal onde são ou estão sendo vivificadas (McLAREN, 1999).

Segundo FREIRE (2001), o ser humano pode e deve ser educado para ouvir suas necessidades de transformação e para saber reconhecer oportunidades de aperfeiçoamento pessoal e interpessoal, podendo ampliar suas potencialidades e qualidades humanas e tomar nas mãos ${ }^{\mathrm{i}}$ o compromisso de transformação da atual realidade social para uma situação em que existam equilíbrio, justiça e igualdade social.

A afirmação de FREIRE (1996) de que "somos seres da transformação e não da adaptação" nos remete ao livro A sombra desta mangueira (FREIRE, 2001), no qual o próprio Paulo Freire reforça que "O inacabamento sem consciência dele engendra o adestramento e o cultivo. Animais são adestrados, plantas são cultivadas, homens e mulheres se educam" (FREIRE, 2001, p. 75). Portanto, a consciência do inacabamento pode produzir adaptação mas também transformação.

Maria Lúcia de Arruda ARANHA diz que "a educação é uma instância mediadora que torna possível a reciprocidade entre indivíduo e sociedade" (1996, p. 15). A partir das relações estabelecidas entre sujeitos são criados padrões de comportamento que podem ser assimilados, aperfeiçoados ou modificados de acordo com os modelos valorizados em determinada geração ou cultura. Contudo, a história futura não precisa necessariamente ser a reprodução da história passada, da história de nossos antepassados ou cópia de outra cultura com a qual se busca a redenção. Quando 
a educação se fundamenta na simples transmissão de informações, crenças e valores estanques, o status quo social permanece inalterado e os modelos estabelecidos se repetem imutáveis ad infinitum. A educação que produz transformação, isto é, que "educa" para a ação transformadora da sociedade emancipando o sujeito é uma educação libertadora baseada na produção de conhecimentos gerados pela investigação dialógica, interativa e antiautoritária entre educadores e educandos que, a partir do respeito pela cultura e pelos princípios da pedagogia crítica, enquanto práxis emancipatória, promove a passagem da consciência ingênua à consciência crítica.

Professores são educadores e as funções desse papel devem ser reavaliadas. Envolvido numa organização escolar formal, o professor tem o compromisso de oportunizar, para si e para seus alunos, a construção das capacidades de análise e síntese, capacidade esta que prepara o sujeito para viver e agir em sociedade, trabalhando partes e vislumbrando o todo complexo. É necessário que o professor tenha em mente que permitir a si e a seus alunos a (des)construção, reconstrução e reformulação de conteúdos é passar de respondedor a questionador, é manter-se reflexivo, questionando sempre o porquê e o para quê, pois o saber construído sobre a relevância e aplicabilidade dos conteúdos e na confiança e poder que o educador outorga aos educandos constitui-se também objeto de transformação social.

O professor é modelo e exemplo para seus alunos, portanto, atitude reflexiva e atitude crítica são essenciais para que os educandos aprendam a conviver dentro de um ambiente de aprendizagem e formação de sujeitos cidadãos. É urgente que cada docente perceba a responsabilidade e o poder ético e moral que carrega consigo. $\mathrm{O}$ professor precisa, também, reconhecer-se como ser e cidadão político e perceber-se responsável pelas atitudes e exemplos com os quais contamina seus alunos.

É urgente alertar os envolvidos no processo educativo sobre a necessidade de mudar o enfoque da relação professor/aluno durante o processo de ensino/aprendizagem de língua estrangeira, principalmente do inglês. Como a língua inglesa tem dominado a comunicação, as relações e o comércio internacional, os interlocutores envolvidos nesse contexto estarão agindo, interagindo e praticando suas capacidades de viver e conviver entre sujeitos de culturas dominantes e culturas 
dominadas. Neste convívio micro, em sala de aula, poderá existir uma predisposição de repetição do modelo macro, isto é, há uma tendência e um risco de reprodução do modelo oprimido-opressor na relação aluno-professor. Assim, as posições de dominador e dominado estariam sendo reforçadas, dificultando a emancipação dos educandos e perpetuando o hábito de adestrar em lugar de educar.

Os motivos que levam as pessoas à aceitarem pacificamente "sua condição" enquanto dominados ou dominadores é terem tido suas posições de opressores e oprimidos constantemente reforçadas, principalmente pelo processo cultural e educativo fixado na transmissão de valores, crenças e conhecimentos, sem oferecerlhes a opção de reconstrução destes conceitos, para que assim pudessem transformálos. A transmissão e aceitação acrítica desta situação é o que impede a transformação da realidade social, realidade esta que prejudica o convívio inclusive entre opressores e dominadores. A alternância das posições sociais de opressor para oprimido e viceversa, na educação permitiria a troca de posições entre dominados e dominadores, oprimidos e opressores e promoveria a percepção de que tais posições não caracterizam a essência das pessoas que as ocupam, mas que são posições conferidas às pessoas socialmente.

O processo educativo deve propiciar que alunos e professores reconheçam-se como sujeitos e objetos ao mesmo tempo, para que assim possam desenvolver a consciência de que nos fala Freire, que somente ao "reconhecer-se como objeto" é que podemos nos "assumir como sujeito" (FREIRE,1996, p. 46). Pois o ser humano se (re)conhece a partir das trocas facilitadas, ou dificultadas, pelos relacionamentos interpessoais nos quais devem ser respeitadas e valorizadas as diferenças, que somam valor aos seres humanos.

Para uma educação crítica integral é ideal que pais e escola compartilhem essa responsabilidade, fazendo com que a pedagogia crítica, que instiga a criação e o desenvolvimento da atitude reflexiva e do espírito crítico, não fique restrita à escola, uma vez que a escola é apenas uma das instâncias onde ocorre a educação. Assim, a família pode ser uma ponte segura entre escola e sociedade, entre a prática formal e informal da pedagogia crítica. 
Portanto, a formação dos educadores, profissionais e/ou informais, deve ser revisitada neste momento de crise na educação mundial, que se reflete em crise social que, muito provavelmente, foi originada pela fragmentação dos saberes da educação em disciplinas isoladas. Essa fragmentação o que não permitiu nem a educadores nem a educandos perceber e trabalhar a complexidade e interdependência dos sistemas organizados dentro do todo. Para tanto, Edgar MORIN (2001) propõe repensar a reforma e reformar o pensamento responsáveis pelo movimento que promoveu a fragmentação do conhecimento em disciplinas isoladas. Ele alerta para o fato de que a complexidade da educação é comparável à complexidade da vida e que a soma das partes não é igual ao todo, mas sim maior que ele.

O Relatório Educação, um tesouro a descobrir elaborado para a UNESCO sob a coordenação de Jacques Delors, assinala que a educação é um processo ao longo da vida, o que legitima a necessidade de se alcançar a harmonia mundial respeitando a Terra e seus habitantes como parte de um todo interligado, interdependente e conectado. Para DELORS (2001), a educação deste milênio deve ser construída sobre quatro pilares: aprender a conhecer; aprender a fazer; aprender a viver juntos; aprender a ser. Assim, cabe aos professores tornarem-se educadores que, como tal, permitirão aos educandos sob suas responsabilidades agirem e interagirem em favor de uma sociedade planetária mais justa e mais igualitária.

\section{Educação para o desenvolvimento sustentável}

Segundo GADOTTI, o conceito de desenvolvimento sustentável foi utilizado pela primeira vez em 1979 numa Assembléia das Nações Unidas para indicar a possibilidade de desenvolvimento que considerasse, além dos aspectos econômicos, as dimensões éticas, políticas, sociais e ambientais. Termos como desenvolvimento sustentável e desenvolvimento humano são adotados para indicar níveis de qualidade de vida como saúde, educação, longevidade, ambiente limpo, maturidade psicológica, espírito comunitário e lazer criativo que, com traços comuns, determinam ações para viabilizar uma sociedade sustentável. GADOTTI define sociedade sustentável "como aquela capaz de satisfazer as necessidades das gerações de hoje sem comprometer a 
capacidade e as oportunidades das gerações futuras" (2000, p. 58).

Lester Brown, fundador do World Watch Institute, estabeleceu relação entre o aumento da consciência planetária e o aumento das oportunidades de trabalho. Brown afirmou que incentivar a preservação ambiental - por meio de políticas de desenvolvimento sustentável do tipo recycle, reduce, reuse - aumenta o nível de oferta de emprego proporcionando assim que mais pessoas tenham oportunidade de viver dignamente. Observa-se que o desenvolvimento sustentável está diretamente ligado à educação integral e à educação em língua inglesa. A interdependência entre educação, desenvolvimento sustentável e língua inglesa é fundamental para a compreensão das relações de poder e formação de habitus (BOURDIEU, 1982 apud JORDÃO 2001, p. 6) em nossa sociedade.

Um possível envolvimento da sociedade neoliberal e capitalista com práticas sustentáveis é tratada por STERLING (2001) como superficial. Segundo ele os envolvimentos neste nível não provocam mudanças, mas sim acomodação; não proporcionam aprendizado, mas sim ignorância; não autorizam reforma mas sim reflexão crítica adaptativa e. obviamente, não propiciam transformação porque não possibilitam a (re)visão crítica do modelo econômico social dominante.

Moacir GADOTTI (2000) chama atenção para a incompatibilidade entre desenvolvimento sustentável e desenvolvimento econômico capitalista, que precisa substituir felicidades gratuitas por felicidades comercializadas cujos objetivos estão centrados no lucro: principal responsável pela degradação do meio ambiente. A grande contradição apontada por Gadotti está no modelo de desenvolvimento ilimitado num planeta com recursos limitados.

O sistema econômico, imposto pela hegemonia norte americana, força a existência de países ricos e pobres, como parte da lógica do sistema. Os imperialistas possuem um padrão capitalista de desenvolvimento no qual não consideram a possibilidade de modelos econômicos alternativos e tampouco refletem sobre a solidariedade devida aos futuros habitantes da Terra, dos quais usurpam a possibilidade de existência que o desenvolvimento dentro de paradigmas sustentáveis poderia proporcionar. 
STERLING e GADOTTI, em suas obras Sustainable education: re-visioning learning and change e Pedagogia da Terra, compartilham da visão da Terra como sendo um elemento vivo a ser respeitado, cuidado e conservado. Esses autores concordam que há uma saída para a construção de um mundo mais pacífico, justo e sustentável e que, sem dúvida, esta saída é a educação. Educação que ensina a viver, a conviver, a conhecer, a fazer, e que ensina principalmente $a$ ser.

A educação para o desenvolvimento sustentável implica em mudança do atual paradigma de desenvolvimento para outro que valorize questões ecológicas e humanistas. A educação humanista sustentável privilegia o ser, reconhece e sustenta a profunda interdependência entre seres humanos e natureza enquanto enfatiza as relações promovidas por uma visão de mundo em que vários aspectos se conectam para formar um todo complexo interdependente. Uma educação humanista considera o interesse pelo bem-estar físico e emocional de educandos e não está direcionada para desenvolver habilidades que servirão como pilares de sustentação para manutenção da globalização, serva do mercado consumista neoliberal que "trabalham juntos para democratizar o sofrimento e destruir a esperança" (McLAREN, 2000, p. 119).

A educação para o desenvolvimento sustentável pode proporcionar a transformação da sociedade competitiva em nova realidade de ordem social, na qual a tônica sejam a cooperação, a tolerância, o respeito e o companheirismo. Assim, pertencendo a um todo complexo, a competitividade deve ceder espaço à cooperatividade; por isso precisamos urgentemente pensar globalmente e agir localmente, desencadeando um processo contínuo, planetário, interdependente e de ação conjunta. Nessas condições, o uso de um idioma único será considerado como elemento facilitador e necessário que viabilizará o entendimento entre povos e nações.

Sob este aspecto é que poderemos nos beneficiar da influência do poder político, militar e econômico exercido primeiramente pelo reino britânico e depois pelo reino encantado do entretenimento, no chão e nas estrelas, de Walt Bush ${ }^{\mathrm{ii}}$, que presentearam o planeta com a quase imposição do uso do inglês para comunicação internacional. 
$\mathrm{O}$ bem estar e o futuro da humanidade dependem do desenvolvimento sustentável que depende da educação complexa, transdisciplinar e voltada para a formação de atitudes e comportamentos ligados ao respeito e valorização de aspectos humanos; é preciso celebrar uma educação que valorize a biodiversidade holística e que considere fundamentais a esperança, a dignidade, a solidariedade, a compreensão.

\section{Educação em língua inglesa}

A aprendizagem de uma língua estrangeira ou segunda língua é um fator importante na educação e na formação do sujeito. A partir da aprendizagem de uma língua estrangeira o educando tem a oportunidade de comparar e refletir melhor sobre sua própria cultura e língua, e como consequiência poderá compreender sua identidade de sujeito e objeto político-social. É também pela aprendizagem de uma segunda língua que se tem oportunidade de conhecer aspectos importantes da própria língua: origens, raízes, influências, razões de alterações lexicais, entre outros. Ao mencionar a aquisição de conceitos científicos, VIGOTSKI (1999, p. 137) afirma que a aprendizagem de "uma língua estrangeira facilita o domínio das formas mais elevadas da língua materna". Portanto, o aprendizado de uma ou mais línguas estrangeiras beneficiará sobremaneira o conhecimento de sutilezas da primeira língua adquirida.

Como a língua é um componente fundamental da cultura, o conhecimento de uma segunda língua contribui de forma significativa para a construção da identidade do aprendiz no momento em que o mesmo tiver a oportunidade de relacionar sua própria língua e cultura com a língua e cultura de outrem. Partindo da relação entre dois idiomas o aluno poderá situar-se melhor no mundo, uma vez que terá a possibilidade de compreender a cultura a qual pertence. Desta maneira, poderemos considerar que o estudo de uma segunda língua faz parte do processo que chamamos de educação integral do ser humano.

Considerando-se tanto a LDB quanto os PCNs, percebemos a importância conferida à língua estrangeira pelas políticas educacionais brasileiras, as quais destacam a necessidade do contato com pelo menos uma língua estrangeira para a formação integral do cidadão (PCN DE LÍNGUA ESTRANGEIRA, p. 41). Devido à 
influência econômica, comercial e cultural, a língua estrangeira escolhida para integrar o currículo da grande maioria das escolas brasileiras é a língua inglesa.

A língua inglesa pode ser considerada como língua franca, língua internacional ou língua global. Contudo, após a pesquisa realizada, optei pela definição e uso da língua inglesa como língua dominante, uma vez que considero este termo eficaz para transmitir a idéia do domínio, da força e da pressão com relação ao uso da língua. Fato este foi observado historicamente por PENNYCOOK (1998) e CANAGARAJAH (1999) ao descreverem as práticas utilizadas pelos colonizadores que partiam de países nos quais a língua inglesa era a língua oficial. A expressão língua dominante mostra, com efeito, tanto a força que a língua inglesa tem ainda hoje no mundo, como a energia daquilo que tem sido praticado pelo principal e mais rico dono desta língua: a manipulação e o domínio econômico, político e também cultural das demais nações, desenvolvidas ou não, do globo terrestre.

Que os povos tenham uma língua comum de comunicação não é fato condenável, muito pelo contrário: aceitar e promover o uso de uma língua dominante para comunicação entre nações pode ser encarado como um mecanismo que produz elementos facilitadores para a troca de informações e experiências entre os povos, além de proporcionar melhor conhecimento e compreensão entre os mesmos. Mas aceitar, a partir daí, que a hegemonia lingüística abra caminho para a intervenção em padrões de comportamento cultural e econômico, como aqueles que têm sido indiretamente impostos aos países do chamado terceiro mundo pelos países dominantes, mais precisamente pelos Estados Unidos da América, é o mesmo que abdicar da própria identidade, dignidade e cidadania.

Dentro da sociedade globalizada produzida pela tão esperada e sonhada modernidade do século XX, e patrocinada pelo imperialismo praticado principalmente por britânicos e americanos, o idioma inglês tem sido um dos aspectos que causam importantes interferências dentro do processo de educação integral dos sujeitos, processo no qual a complexidade das interações sociais e as suas implicações aumentam sobremaneira (PENNYCOOK, 1994).

$\mathrm{Na}$ realidade escolar, o professor, como educador do espírito crítico, deve 
estimular seus alunos a conhecer os motivos que levam à aceitação pacífica da subordinação por parte dos dominados. Em conjunto, professor e alunos podem tentar compreender como o mecanismo do poder é construído e mantido atualmente na sociedade ocidental; juntos, podem analisar qual o papel da educação crítica na transformação do modelo social e caracterizar o processo de construção de uma sociedade equânime que promova a transformação da sociedade globalizada em espaço libertador.

O fato de ensinar inglês, não mais como a língua dos americanos e ingleses, mas sim como idioma dominante nas interações e nas relações entre países e entre sujeitos de diferentes nacionalidades, pode ser motivo de alívio para muitos professores conscientes da manipulação causada pelo domínio do idioma e, especialmente, da cultura do big brother. Em geral, os professores com espírito crítico mais aguçado sentem-se desconfortáveis em ensinar juntamente com a língua, a cultura imperialista dos native speakers do norte, responsáveis pela colonização e dominação intelectual e econômica de muitos povos e nações.

\section{Considerações finais}

A observação de questões e de dicotomias relacionadas com aspectos importantes como educação, mais especificamente educação para o desenvolvimento sustentável e ensino e aprendizagem de língua estrangeira promovem oportunidade para desenvolver uma visão geral, holística da realidade em que vivemos.

FREIRE (2001, p. 25) confirma a necessidade de construir e fortalecer, a partir da educação, a identidade local dos sujeitos para mais tarde poder inseri-los na sociedade plural e globalizada: "Sou primeiro recifense, pernambucano, nordestino. Depois, brasileiro, latino-americano, gente do mundo". Somente depois de reconhecerse local, o sujeito poderá reconhecer-se inserido numa realidade universal e complexa. Tal complexidade advém da conexão entre nações e culturas e do desenvolvimento dos meios de comunicação. O fortalecimento da identidade local do sujeito torna possível a interação e a relação de complementaridade entre sujeitos e suas responsabilidades na construção e manutenção tanto da identidade e cidadania locais como da identidade 
e cidadania planetárias (SILVA, 2002).

Outro aspecto extremamente pertinente a tais questões refere-se à educação como elemento básico da interdependência, e até sobreposição, entre algumas das necessidades humanas mais urgentes deste momento, quer sejam educação propriamente dita, desenvolvimento sustentável e língua inglesa, esta considerada indispensável, pois sendo a língua dominante que permite a comunicação internacional, poderá ser usada como elemento chave no entendimento entre os seres humanos para a construção de um futuro mais justo e equilibrado.

Ao interiorizarmos o fato observado no início dos anos 50 pelo mestre Mahatma Gandhi, que dizia serem suficientes os recursos naturais da Terra para todos, menos para o potencial destrutivo dos consumistas vorazes gerados pelo desenvolvimento capitalista (GADOTTI, 2000), e a realidade de sermos habitantes de um planeta com recursos finitos, podemos educar e educar-nos para o uso racional dos recursos. Recursos que, embora escassos, podem alguns deles ser renováveis, enquanto outros recursos dependem apenas de uma atitude de não-desperdício para continuarem à disposição dos seres humanos. A educação deverá, portanto, enfatizar a responsabilidade pelo coletivo e pelo individual ao mesmo tempo, uma vez que devemos ser educados tanto para a emancipação quanto para a interdependência.

Emancipados e interdependentes, deveremos proporcionar uma educação de qualidade, facilitada a todas as classes, instâncias e esferas sociais, com o objetivo de transformar a atual sociedade competitiva em uma nova realidade social, voltada para a cooperação, o respeito e o companheirismo.

De fato, é somente com uma educação multicultural, mais justa, mais fraterna, mais igual que teremos chance de dar resposta às necessidades culturais e específicas de cada comunidade local objetivando, cada qual a seu modo, dar continuidade à vida na Terra. Para que isto aconteça, o ser humano precisa ser educado dentro de uma filosofia humanista de respeito, solidariedade e abertura ao outro, ao diferente, enquanto deve estar preparado para assumir a responsabilidade de saber, de perceber e de reconhecer suas oportunidades de escolha (DELORS, 2001).

A língua dominante para a relação e comunicação entre povos e nações pode 
ser um instrumento aliado e essencial, que permite acordos e tratados objetivando a melhoria da qualidade de vida para todos os habitantes desse imenso planeta Terra. Como usuários da língua dominante, pode-se optar pela participação em movimentos e ações que visam a integração de todas as nações, inclusive das comunidades menos desenvolvidas economicamente, em prol da construção de um futuro mais justo e equilibrado, baseado nos princípios da educação crítica e do desenvolvimento sustentável. O sujeito pode tornar-se agente de transformação social ao invés de ser apenas espectador, membro de uma audiência que, por não entender a língua, não pode sequer opinar sobre as decisões tomadas pelos líderes dos países ricos e poderosos que, coincidentemente, são também donos da língua dominante. A percepção de trabalhar com objetivos concretos e comuns, em espaço compartilhável, pode ajudar a criar uma atmosfera de entendimento e cordialidade entre povos e nações, mesmo usando o idioma dominante.

Dentro do contexto multidisciplinar, o professor de língua inglesa é dentre todos os outros professores especialistas aquele que mais pode colaborar para uma educação plural interdisciplinar porque, partindo do ensino da língua dominante, ele poderá incorporar conteúdos de outras disciplinas, tais como história, geografia, matemática, ciências, português. Todos os professores, inclusive os que ainda mantêm uma atitude de professor-especialista, são responsáveis não apenas pelos conteúdos programáticos a cargo de suas disciplinas, mas também pela atitude dos alunos em relação à comunidade a qual pertencem e, conseqüentemente, pela comunidade planetária.

É dever do professor-educador, especialmente do professor-educador em língua dominante, lembrar aos alunos que ao se submeter às regras gramaticais de uma língua estrangeira não é necessário entregar-se à cultura dessa língua, mas, conhecendo-a, (re)conhecer e valorizar a cultura de sua própria nação, da nação a qual pertence.

Conscientes de que somente por meio de uma educação crítica que permite a reflexão e a educação de sujeitos críticos e conscientes poderemos estruturar uma sociedade mais humana e por isso mais justa, mais fraterna, mais igual e que se 
compromete com a melhora da qualidade de vida das gerações futuras, o ser humano poderá ter chance de dar continuidade à vida na Terra.

Portanto, lançar um olhar alternativo, com estranhamento, para os aspectos educacionais e econômicos ora dominantes é fundamental. Assim como é essencial que o ser humano seja educado para o desenvolvimento sustentável, em língua dominante, e que esteja preparado para a responsabilidade de saber perceber e de saber reconhecer suas oportunidades de escolha.

\section{REFERÊNCIAS BIBLIOGRÁFICAS}

ARANHA, M. História da educação. 2.ed. São Paulo: Moderna, 1996.

CANAGARAJAH, A. Resisting linguistic imperialism in English teaching. Oxford: Oxford University Press, 1999.

DELORS, J. et al. Educação: um tesouro a descobrir. 6.ed. São Paulo: Cortez, 2001.

FREIRE, P. À sombra desta mangueira. 4.ed. São Paulo: Olhodagua, 2001.

Pedagogia da autonomia: saberes necessários à prática educativa. 21.ed. São Paulo: Paz e Terra, 1996.

GADOTTI, M. Pedagogia da Terra. 2.ed. São Paulo: Peirópolis, 2000.

GIROUX, H. Pedagogia crítica como projeto de profecia exemplar: cultura e política no novo milênio. In: IMBERNÓN, F. A educação no século XXI: os desafios do futuro imediato. 2.ed. Porto Alegre: Artes Médicas, 2000.

McLAREN, P. Pedagogia revolucionária em tempos pós-revolucionários: repensar a econômia política da educação crítica. In: IMBERNÓN, F. A educação no século XXI. Os desafios do futuro imediato. 2.ed. Porto Alegre: Artes Médicas, 2000. 
McLAREN, P. Utopias provisórias: as pedagogias críticas num cenário pós-colonial. Petrópolis: Vozes, 1999.

MORIN, E. A cabeça bem-feita, repensar a reforma, reformar o pensamento. 5.ed. Rio de Janeiro: Bertrand Brasil, 2001.

PENNYCOOK, A. English and the discourses of colonialism. London: Routledge, 1998.

STERLING, S. Sustainable education: re-visioning learning and change. Bristol: Green Books, 2001.

VIGOTSKI, L. Pensamento e linguagem. 2.ed. São Paulo: Martins Fontes, 1999.

i “Tomar nas mãos” significa aqui ser sujeito e objeto da própria educação, ser agente.

ii Alusão à cultura do entretenimento de Walt Disney somada à cultura bélica da família Bush, George e George W., pai e filho adeptos de demonstrações irracionais para legitimação do poder imperial americano, por meio de manobras militares promovidas longe dos territórios por eles administrados (2003). 